\title{
Improved Inverse Design Method for Thin-wall Hollow Profiled Polymer Extrusion Die Based on
}

\section{FEM-CFD Simulations}

\author{
Guangdong Zhang ${ }^{1,2 *}$, Xiang Huang ${ }^{1}$, Shuanggao $\mathrm{Li}^{1}$, Chao Xia ${ }^{3}$, Tong Deng ${ }^{4}$ \\ ${ }^{1}$ College of Mechanical and Electrical Engineering, Nanjing University of Aeronautics \& Astronautics, China \\ ${ }^{2}$ School of Mechanical Engineering, Yancheng Institute of Technology, China \\ ${ }^{3}$ Shanghai Bethlehem Plastic Co. Ltd., China \\ ${ }^{4}$ The Wolfson Centre for Bulk Solids Handling Technology, Faculty of Engineering and Science, University \\ of Greenwich, UK
}

\begin{abstract}
Extrusion process has excellent capability in continuous manufactures with high production volume, low cost, and steady quality for very complex cross-sectional products. However, manufacturing a proper extrusion die is challenging, but essential for good quality products, which needs to consider many influence factors in the die design. This paper shows an improved inverse design method for thin-wall hollow profiled polymer extrusion die by using computational fluid dynamics simulation. Also, design criteria of the inverse design method for extrusion die are proposed and discussed. The simulation results show that the thickness of the die lip gap can be enlarged with the decreasing of the inlet flow rate. Additionally, it shows that the geometry profile of the die lip gap can be widened with the increasing of the length of the free jet. The analytical results have been verified by experiments and show a good agreement. It is concluded that the improved inverse design method with FEM-CFD simulations can provide better accuracy and significantly reduce the manufacturing difficulty of micro and thin-walled extrusion die.
\end{abstract}

Keywords: inverse design; design criteria; profile extrusion dies; FEM-CFD; Polyflow.

\section{Introduction}

Compared to other polymer processing technologies, polymer extrusion has many advantages and huge application prospects, which has been widely used in industry [1]. The main advantage of the polymer extrusion process is continuously manufactured uniform cross-sectional shapes with high production volume, low cost, and steady quality. With the above benefits, the polymer extrusion products have been widely applied in the field of construction, lighting, automobile, medical and so on. Generally, the extrusion process mainly includes raw material melting, forming, cooling and shaping, drawing and cutting of the products. According to the types of the extrudate, there are different types of extrusion dies [1] [2] [3] such as pipe dies, sheet dies, spiral mandrel dies, and profile dies, etc. One of the complex extrudates is the profile, such as automobile weatherstrip[4], tire components [5], and hollow profile [6].

A major problem in polymer extrusion process is die swell due to velocity profile rearrangement

*Corresponding author: E-mail: gdzhang@nuaa.edu.cn, Tel: +86 13951558783 
and recovery of the elastic deformation [7]. The degree of die swell is usually described by die swell ratio, which is defined as $\mathrm{R}_{S}=S_{e x} / S_{0}$, where $S_{e x}$ is cross-section area of the extrudate and $S_{0}$ is cross-section area of the extrusion die gap. The die swell ratio is mainly influenced by material properties, process conditions and deformation history of the material in the extrusion die. Therefore, design of a proper die is essential for quality of the products with correct dimension of the profile. In the past, lots of efforts have been made by using a trial-and-error procedure, which need enormous time and result in huge costs [8]. Recently development of numerical analysis technology has significantly improved design efficiency of the sophisticated geometry profile extrusion die [9] [10] [11] [12], which remarkably reduce the numbers of trials and the total production costs.

Because of die swell, outline of the extrudate is different from the die exit, which manifests as profile distortion. To achieve a qualified outline of extrudate, there are two conventional methods which can be used to deal with the die swell problem in the industry. The first method is to achieve a flow balance at the die exit by adjusting the die geometry [6]. This method is an optimization process, which aims to maximize the flow uniformity at the die exit by geometric modification of the die contour [13] [14]. Based on sectional areas divided, the flow balance method should strike a balance between the thicker sub-areas where have a higher flow-speed and the thinner sub-areas where have a lower flow-speed, and eventually to make the average velocity homogeneously in all sub-areas of the die lip.

The flow-balance method has been widely used. Pauli et al. [15] and Siegbert et al. [16] adopted space-time finite element method to the optimization of die design, which flow balance and homogeneous die swell were used as the design objectives. Yilmaz et al. [17] took uniformity of velocity distribution at the die exit as an objective function. Carneiro et al. [18] proposed a method only by using OpenFOAM et al. open-source software to aid the design of complex extrusion dies. $\mathrm{Mu}$ et al. [6] analyzed the influence of the die geometric parameters on the velocity distribution uniformity. Rajkumar et al. [19] introduced a novel method to balance the flow distribution in complex extrusion dies, which the profile cross-section geometry should be divided into L and $\mathrm{T}$ shaped profiles. However, the major drawback of the flow balance method is its computational domain that only includes the die domain, not the free jet domain. Therefore, the die-swell effect and consequent extrusion deformation are not taken into account.

The second method attempts to compensate for the effects of die swell, which is called inverse design method. Covas et al. [20] mentioned a strategy to correct the die lip by considering the die swell effect. Legat et al. [21] discussed the inverse extrusion problem (IEP), which was to find a required die shape through implicit Newton-Raphson iterative method. Gifford [22] suggested that the design of complex profile extrusion dies often involved not only "balancing" the die but also compensating for the effects of die swell. These efforts [23] show that this method can improve the design of profile extrusion dies for complex shapes, but the main difficulty is limited methodological guidance available, especially for the criteria of the inverse design for micro and thin-walled extrusion die.

In this paper, the inverse design method was used for finding an optimal solution of a thin-wall 
hollow profiled extrusion die by using computational fluid dynamics simulation. Based on the simulation results, criteria of the inverse design method of extrusion die were proposed and discussed. Experiment study was carried out, and the measured values of geometric dimensions of the extruded parts were obtained, which show a good agreement with the expectation.

\section{Problems in Design of Extrusion Die}

In design of an extrusion die, there are many difficulties occurred, which are mainly the die swell and consequent distortion in different areas when the material leaves the die. For thin-wall hollow profile, one major problem is the thickness control of the die lip gap where is too thin to do the die repair. A typical example of thin-wall hollow profile is shown in Fig. 1, which is investigated in the following study.

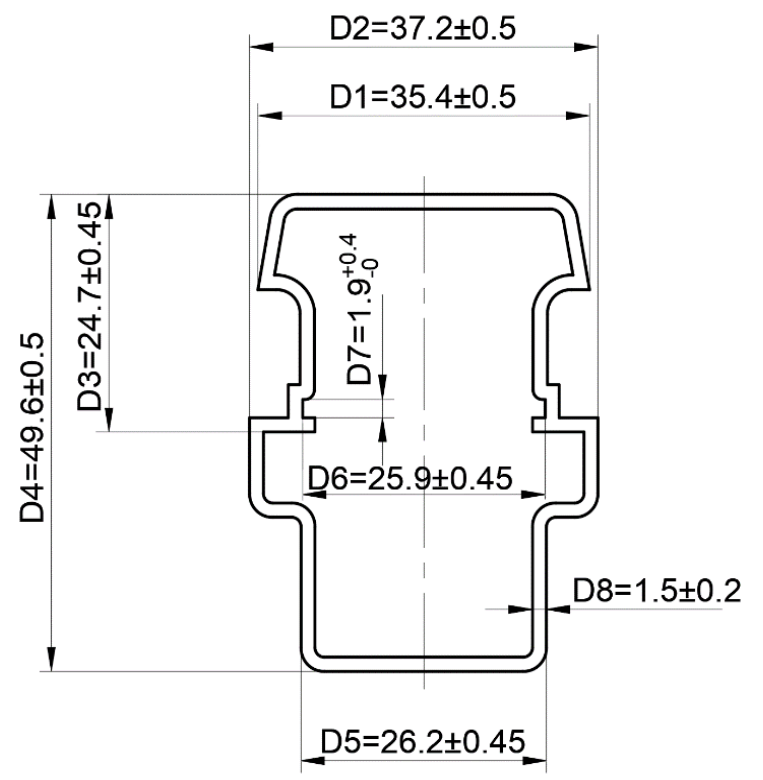

Fig. 1: Cross-sectional geometric parameters of a thin-wall hollow profile (dimension in $\mathrm{mm}$ )

This profile is a transparent plastic light cover and installed in the aluminum strip profile. The hollow profile has almost a uniform wall thickness of $1.5 \mathrm{~mm}$. From previous experiences, the required wall thickness of the profile is hard to be achieved, and it need be adjusted by the successive approximation of the die repair. If the wall thickness deviation is too big, it will increases the times of die repair and even causes die failures. Up to now, there is no effective method to solve this problem, neither the flow balance method nor inverse design method.

\section{CFD Model for Extrusion Process}

To solve the problem effectively, a CFD model is established based on the assumption that the polymer melts are incompressible laminar viscous non-Newtonian fluids flowing under isothermal conditions. Also, the effect of inertia and gravity has not been considered in the CFD simulation. 


\subsection{Material properties}

The product material shown in Fig. 1 is polycarbonate (Makrolon ET3113). Its melt temperature is 300 degrees Celsius, and melt density is $1.02 \mathrm{~g} / \mathrm{cm}^{3}$. Polycarbonate melts are high viscous nonNewtonian fluids, so elasticity can be neglected in numerical simulation. The shear viscosity $\eta(\dot{\gamma})$ in Eq. 1 is a function of the second invariant of the rate of deformation tensor using the Bird-Carreau viscous model for the shear-rate dependence of viscosity.

$$
\eta(\dot{\gamma})=\eta_{\infty}+\frac{\eta_{0}-\eta_{\infty}}{\left(1+(\lambda \dot{\gamma})^{2}\right)^{(1-n) / 2}}
$$

where $\eta_{\infty}$ is infinite-shear viscosity $(0 \mathrm{~Pa} \cdot \mathrm{s}), \eta_{0}$ is zero-shea viscosity (707 $\left.\mathrm{Pa} \cdot \mathrm{s}\right), \lambda$ is relaxation time $(0.00243 \mathrm{~s})$, and $n$ is power-law index $(0.426)$. The rheological parameters were obtained from Computer Aided Material Preselection by Uniform Standards (CAMPUS) database [27], and checked by using a rheometer (HAAKE RS600, Thermo Electron, USA) from East China University of Science and Technology.

\subsection{Boundary conditions}

Conventionally, flow runner of a profiled extrusion die often included adapter, transition section, pre-parallel section, parallel section (die land) and the extrusion mandrel for hollow profile [28]. As mentioned by Dai et al. [29], if the length of the parallel section is long enough, the influence of the transition section and the pre-parallel section on the extrusion process can be neglected. So in this simulation, the parallel section (Die Land domain) and the free surface (Free Jet Domain) were included in the computational domain (shown in Fig. 2). The length of Die Land domain and Free Jet domain are $L_{D}$ and $L_{F}$, respectively. Owing to the symmetry of the problem, a symmetry boundary condition is specified for the sake of simplicity. In Die Land domain, the polymer melts enter the die from Inlet and leave Die Lip, concurrently the no-slip boundary condition is applied at Wall. The Die Lip is the interface between Die Land domain and Free Jet domain. After the polymer melt leaves the Die Lip, a die swell occurs and the polymer melts move toward the Outlet of the Free Jet under a traction force. Finally, a Free Surface is formed after the polymer melts have been extruded.

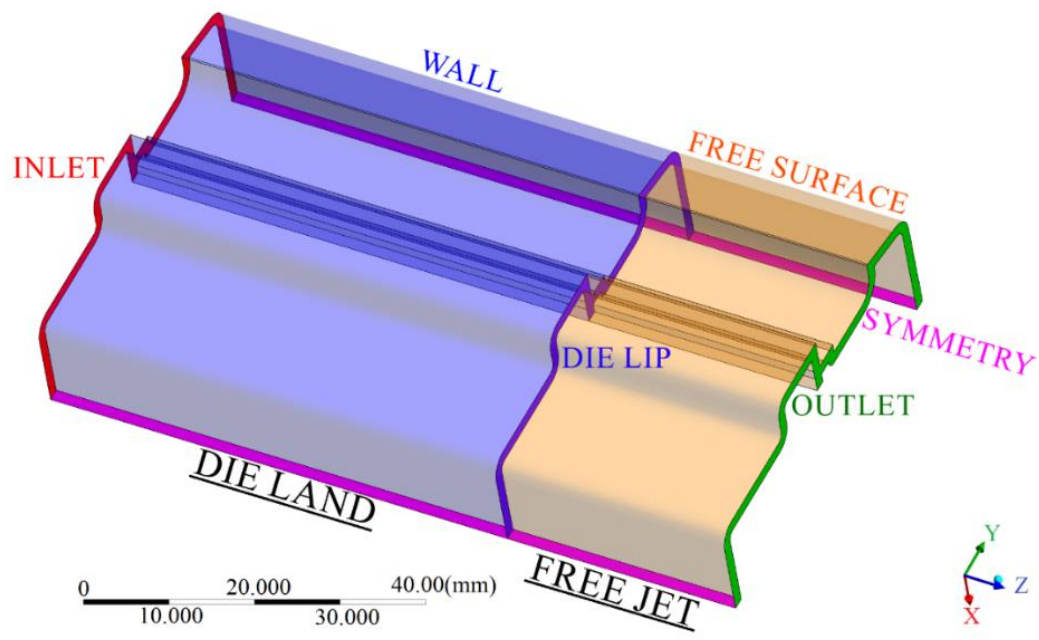

Fig. 2: 3D geometry and boundary conditions in the simulation 
The boundary conditions were specified in ANSYS Polyflow:

Boundary 1: Inlet. The fully developed velocity profile was computed by the ANSYS Polyflow and with the volumetric flow rate $\mathrm{Q}$ in $\mathrm{mm}^{3} / \mathrm{s}$.

Boundary 2: Outlet, at which a constant drawing velocity or force was imposed.

Boundary 3: Plane of symmetry, which has the zero tangential force $f_{s}=0$, and normal displacement $\mathrm{d}_{\mathrm{n}}=0$.

Boundary 4: Free surface, where does the die swell happen. Arbitrary Lagrangian-Eulerian (ALE) interface-tracking method and Optimesh-3D remeshing method were used for simulating a free surface in ANSYS Polyflow.

Boundary 5: Wall with the no-slip boundary condition.

\subsection{Mesh Generation}

Taking into account of mesh quality and computational efficiency, the 3D model was meshed with hexahedral elements using ANSYS Meshing module. Because of its symmetric property, only half of the geometry has been meshed (see Fig. 3).

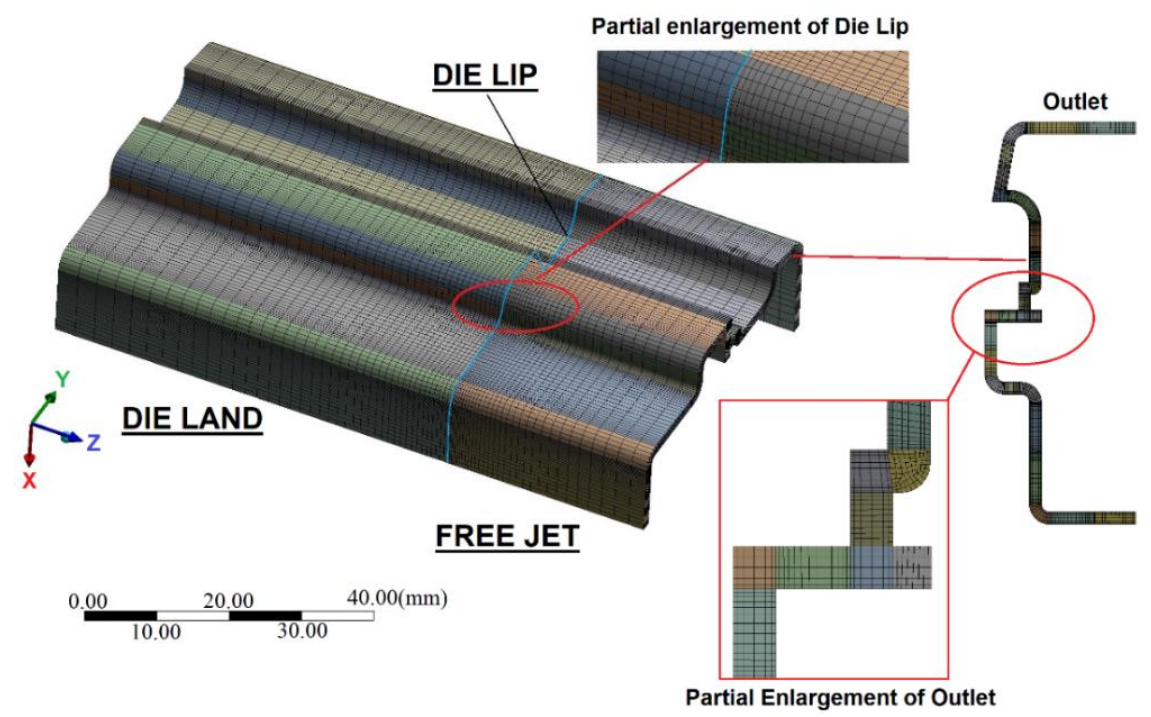

Fig. 3: Mesh Generation for the Extrusion Simulation

The length of the die land is $60 \mathrm{~mm}$ and the free jet is $30 \mathrm{~mm}$. The total number of elements and nodes are 185325 and 215840 respectively. Around the die lip area, the meshes have been refined to achieve smoother results, because of large deformation around the die lip zone. From the results of mesh convergence study, the effect of grid accuracy on the simulation results is within $0.3 \%$ if the number of nodes in the thickness direction is more than six.

\section{CFD Simulation Results}

\subsection{Prediction of extrudate swell}

In design of an extrusion die, engineers need to know the deformation of the extrudate occurred, 
which is called prediction of extrudate swell [30] [31]. With CFD simulation using finite element software ANSYS Polyflow, the prediction of extrudate swell can be achieved. The boundary conditions are defined: the volumetric flow rate $Q$ of the INLET is $1321.1 \mathrm{~mm}^{3} / \mathrm{s}$ based on the product of the area of die lip gap and the expected extrusion velocity of $10 \mathrm{~mm} / \mathrm{s}$, and the outlet of the Free Jet has zero drawing force applied.

It can be found that the velocity distribution at the die exit is nearly balanced from the simulation results shown in Fig. 4. However, there is a high velocity region at the middle of the die exit where the maximum velocity is $18.25 \mathrm{~mm} / \mathrm{s}$. Due to velocity redistribution out of the die exit, a local higher velocity results in a larger extrusion distortion [1]. The average velocity at the Die Lip of the Die Land is reduced from $8.27 \mathrm{~mm} / \mathrm{s}$ to $7.95 \mathrm{~mm} / \mathrm{s}$ at the outlet of Free Jet. Meanwhile, the cross-sectional area is increased from $132.018 \mathrm{~mm}^{2}$ of the die lip to $166.568 \mathrm{~mm}^{2}$ of the extrudate, and thus the die swell ratio $\left(\mathrm{R}_{S}=S_{\text {ex }} / S_{0}\right)$ in this simulation is 1.262 .

Because the thickness of the die lip is constant and the thickness of the extrudate is basically uniform except for the corner sections, the thickness at the middle of the six straight sections of the extrudate was used to obtain an average thickness (see Fig.4). It is shown that the average thickness is increased from $1.5 \mathrm{~mm}$ at the die lip gap to $1.813 \mathrm{~mm}$ at the extrudate.

EXTRUDATE

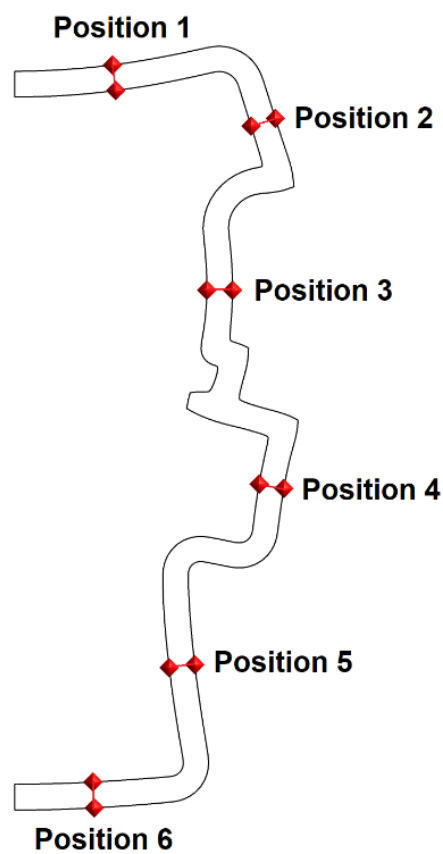

EXTRUDATE

(Thickness $1.81 \mathrm{~mm}$ )

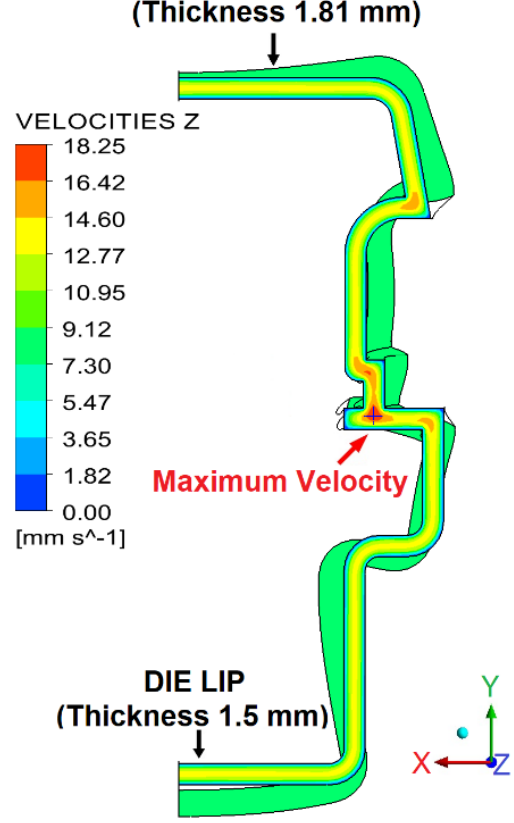

$\frac{0}{5.000} \frac{10.000}{15.000} 20.000(\mathrm{~mm})$

Fig. 4: Six locations of the die lip (left) and Velocity distribution at the die lip and extrudate swell prediction (right)

For the results, it shows that the extrusion deformation and thickness swell are unacceptable, and compensation is needed for the profile extrusion die. Due to the complexity of the hollow profile, it is hard to get the right dimension of extrudate by the optimization method for flow balance. 


\subsection{Inverse design method}

An inverse design method has been applied for finding a possible solution of the extrusion die design to produce the desired profile after the die swell happened. The cross section of the extrudate is taken as input and the extrusion die lip as output in the inverse extrusion simulation. The boundary conditions are the same as the previous ones in section 4.1. As the expected extrusion velocity of 10 $\mathrm{mm} / \mathrm{s}$ and the expected area of Outlet is $132.11 \mathrm{~mm}^{2}$, the volumetric flow rate of the Outlet is 1321.1 $\mathrm{mm}^{3} / \mathrm{s}$. By continuity equations for incompressible fluids, volumetric flow rate from Inlet to Outlet is constant. Therefore, the volumetric flow rate $\mathrm{Q}$ of the Inlet is $1321.1 \mathrm{~mm}^{3} / \mathrm{s}$. Due to the application of drawing force may impact the simulation results, in this case the Outlet of the Free Jet has zero drawing force applied. Importantly, the inverse prediction should be activated in Die Land domain to implement the inverse design of extrusion die.

The profile of the die lip gap is similar to the required profile of the extrudate as shown in Fig. 5. The simulation results show that the cross-sectional area of the die lip is $105.187 \mathrm{~mm}^{2}$, compared with $132.018 \mathrm{~mm}^{2}$ of the extrudate, and therefore the die swell ratio here is 1.255 . Due to the effect of die swell, the average velocity was reduced from $10.41 \mathrm{~mm} / \mathrm{s}$ at the Die Lip to $9.99 \mathrm{~mm} / \mathrm{s}$ at the outlet of Free Jet. Meanwhile, average thickness of the die lip gap is $1.20 \mathrm{~mm}$, which leads to a difficulty in manufacture of the extrusion die. Here, the thickness at the middle of the six straight sections of the die lip was used for calculating an average value.

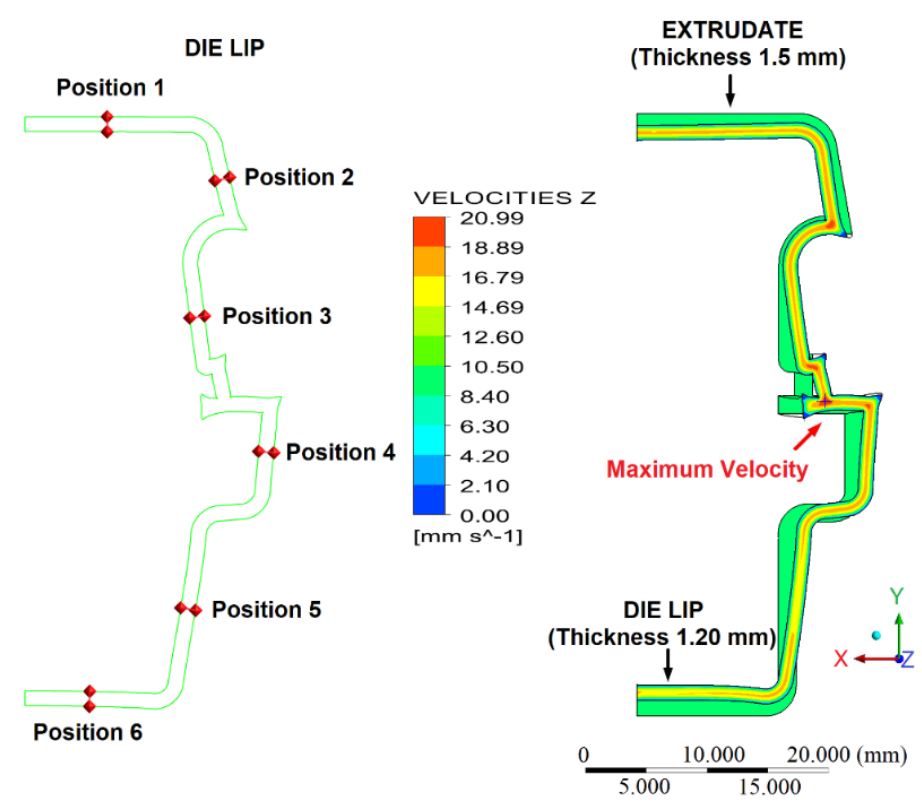

Fig. 5: Six locations of the die lip (left) and Velocity distribution and profile geometry of the die lip by inverse design (right)

\subsection{Improved Inverse Design Method and Design Criteria}

In simulation results shown in Fig. 5, the drawing velocity has not been considered. If the drawing velocity applied at the Outlet is larger than $9.99 \mathrm{~mm} / \mathrm{s}$, the extrudate will shrink in the crosssection dimensions. Instead, if the drawing velocity remains constant, the reduction of the Inlet 
volumetric flow rate $\mathrm{Q}$ will also result in the decrease of velocity at the die lip. Consequently, the extrudate will shrink too. Thus, the dimension of the die lip gap should be enlarged to compensate for the shrinkage. In the case, if the thickness of the die lip needs to increase, the volumetric flow rate of Inlet must decrease or the drawing velocity must increase. As the increase of drawing velocity results in the subsequent difficulty of calibration and cooling, the approach of reducing the Inlet volumetric flow rate is selected for the above purpose.

According to the above analysis, the relationship of Inlet volumetric flow rate with the thickness of die lip at six different positions (shown in Figure 5.) is studied, as illustrated in Table 1.The volumetric flow rate $Q$ of the Inlet is changed from $1100 \mathrm{~mm}^{3} / \mathrm{s}$ to $1400 \mathrm{~mm}^{3} / \mathrm{s}$. Also a constant drawing velocity $(10 \mathrm{~mm} / \mathrm{s})$ has been applied at the Outlet. For the simulation results, the thickness at different positions with the same flow rate condition is nearly uniform, so the average thickness of the die lip can be used for subsequent discussion. Also, the results show that the average thickness of the die lip decreases with the increase of inlet flow rate.

Table 1. Variation of thickness of die lip at different positions with Inlet volumetric flow rate.

\begin{tabular}{cccccccc}
\hline $\begin{array}{c}\text { Flow Rate } \\
{[\mathrm{mm} / \mathrm{s}]}\end{array}$ & $\begin{array}{c}\text { Average } \\
{[\mathrm{mm}]}\end{array}$ & $\begin{array}{c}\text { Position1 } \\
{[\mathrm{mm}]}\end{array}$ & $\begin{array}{c}\text { Position2 } \\
{[\mathrm{mm}]}\end{array}$ & $\begin{array}{c}\text { Position3 } \\
{[\mathrm{mm}]}\end{array}$ & $\begin{array}{c}\text { Position4 } \\
{[\mathrm{mm}]}\end{array}$ & $\begin{array}{c}\text { Position5 } \\
{[\mathrm{mm}]}\end{array}$ & $\begin{array}{c}\text { Position6 } \\
{[\mathrm{mm}]}\end{array}$ \\
\hline 1100 & 1.76 & 1.78 & 1.76 & 1.74 & 1.76 & 1.76 & 1.77 \\
1150 & 1.66 & 1.67 & 1.66 & 1.64 & 1.66 & 1.66 & 1.67 \\
1200 & 1.57 & 1.57 & 1.57 & 1.55 & 1.57 & 1.57 & 1.57 \\
1250 & 1.48 & 1.49 & 1.49 & 1.47 & 1.49 & 1.48 & 1.49 \\
1300 & 1.41 & 1.41 & 1.41 & 1.39 & 1.41 & 1.41 & 1.41 \\
1350 & 1.34 & 1.34 & 1.35 & 1.32 & 1.35 & 1.34 & 1.34 \\
1400 & 1.28 & 1.28 & 1.28 & 1.26 & 1.28 & 1.28 & 1.28 \\
\hline
\end{tabular}

For convenience, thickness swell ratio and length swell ratio are defined in Eq. 2 and 3:

$$
\mathrm{R}_{T S}=\frac{T_{e x}}{T_{0}}
$$

where $T_{e x}$ is average thickness of extrudate and $T_{0}$ is average thickness of die lip.

$$
\mathrm{R}_{L S}=\frac{L_{e x}}{L_{0}}
$$

where $L_{e x}, L_{0}$ is development length along the centreline of extrudate and die lip, respectively.

It is difficult to measure the development lengths along the centreline from the results. However, if small branches of the extrudate can be ignored, area of extrudate is approximately equal to the thickness of extrudate times the development length along the centreline of extrudate $\left(S_{e x}=\right.$ $\left.L_{e x} \times T_{e x}\right)$. In the same way, area of die lip can be defined as $S_{0}=L_{0} \times T_{0}$. Thus, the length swell ratio can be formulated as:

$$
\mathrm{R}_{L S}=\frac{L_{e x}}{L_{0}}=\frac{S_{e x} / T_{e x}}{S_{0} / T_{0}}=\frac{S_{e x} / S_{0}}{T_{e x} / T_{0}}=\frac{\mathrm{R}_{S}}{\mathrm{R}_{T S}}
$$

The relationship of die swell ratio $\left(\mathrm{R}_{S}=S_{e x} / S_{0}\right)$, thickness swell ratio $\left(\mathrm{R}_{T S}\right)$ and length swell ratio $\left(\mathrm{R}_{L S}\right)$ with inlet volumetric flow rate has been studied, as shown in Fig.6, which is useful for guidance of the profile extrusion die design and dimensional control of the extrudate. 


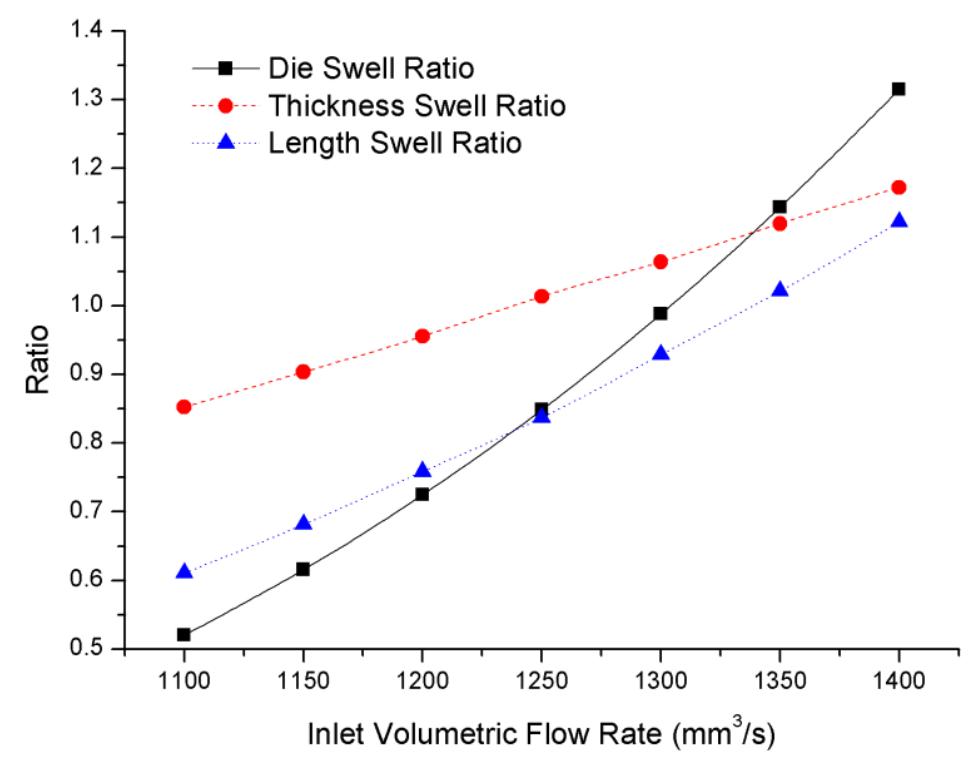

Fig. 6: Die Swell Ratio, Thickness Swell Ratio and Length Swell Ratio with Inlet Volumetric Flow Rate

The Fig. 6 indicates that, when the inlet flow rate increase from $1100 \mathrm{~mm}^{3} / \mathrm{s}$ to $1400 \mathrm{~mm}^{3} / \mathrm{s}$, the die swell ratio increase from 0.52 to 1.31 , while the thickness swell ratio rises from 0.85 to 1.17 , and the length swell ratio expands from 0.61 to 1.12 , correspondingly. Compared with thickness swell ratio, the length swell ratio is smaller and more sensitive to the variation of inlet volumetric flow rate. In other words, in the inverse design of extrusion die, the variation ratio of development length along the centreline is bigger than thickness of die lip, which can be found in equation (2) and (3). Therefore, the length swell ratio can represent the degree of extrusion deformation.

Design criteria of improved inverse design of the extrusion die must be: (1) maximum thickness of die lip and (2) minimum extrusion deformation. In other words, the thickness swell ratio should be minimized, and the length swell ratio need to be close to one. However, the above criteria cannot be satisfied together, as shown in Fig. 7. Therefore, the design criterion needs to be that the thickness swell ratio is equal to one $\left(\mathrm{R}_{T S}=1\right)$, which means that the die swell ratio and length swell ratio are equal $\left(\mathrm{R}_{S}=\mathrm{R}_{L S}\right)$. The optimum solution of inlet flow rate can be found, which is equal to $1250 \mathrm{~mm}^{3} / \mathrm{s}$.

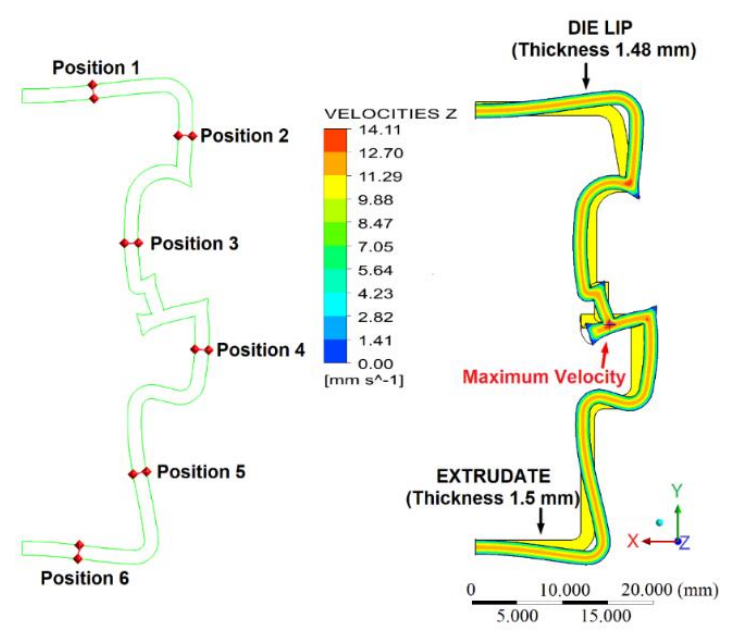

Fig.7 Six locations of the die lip (left) and Velocity distribution and profile geometry of the enlarged die lip (right). 
The simulation results of the optimum solution are shown in Fig. 7, where the die swell ratio is reduced to 0.848 . The thickness of the die lip gap is $1.48 \mathrm{~mm}$, compared with the $1.5 \mathrm{~mm}$ of the extrudate. The distortion of the die lip gap is acceptable which is eligible for the manufacture of the extrusion die. By using this criterion, the manufacturing difficulty of the die is effectively reduced, and the extrusion deformation is within acceptable range. This simulation results will be used for subsequent experimental verification.

\section{Discussion}

With the decrease of the Inlet flow rate, the distortion of the die lip gap will increases, as shown in Fig. 8. When the Inlet volumetric flow rate $\mathrm{Q}$ is less than $1100 \mathrm{~mm}^{3} / \mathrm{s}$, the die lip gap will overlap itself at the center of the die lip, which is unacceptable in the design of extrusion die. The main reason is that the length swell ratio is quickly reduced as Inlet flow rate decreased, and thus the development length along the centreline of die lip will be elongated and twist itself in a limited space.
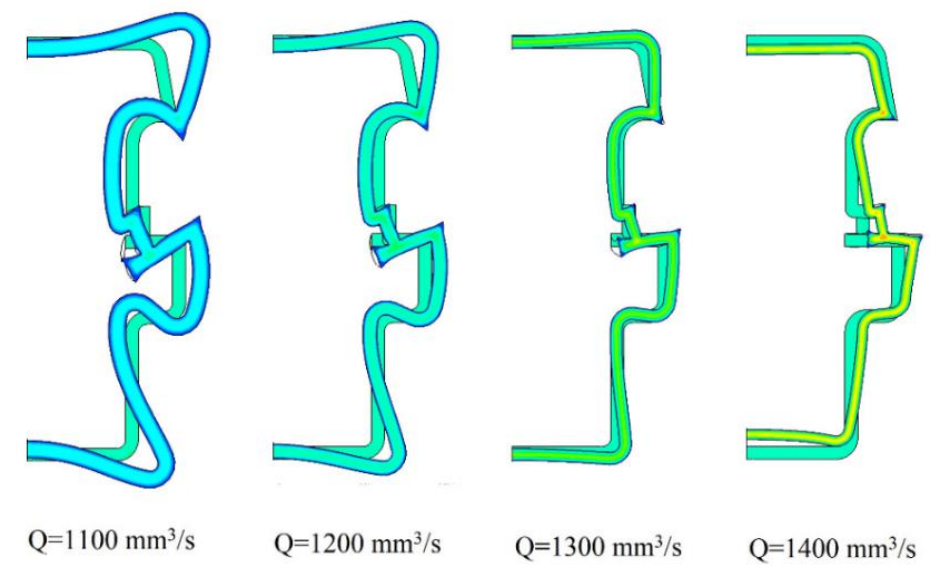

Fig. 8: Die Lip gaps compared at different inlet volumetric flow rate $\mathrm{Q}$

In the inverse design of extrusion die, the length of Die Land and Free Jet will also have a certain impact. As the length of the Die Land $\left(\mathrm{L}_{D}\right)$ increases, the pressure drop in the profile extrusion die increases accordingly, as described previously [32]. When the length of Free Jet ( $\left.L_{F}\right)$ increased, the geometry profile of the die lip gap will be enlarged, but the thickness of the die lip will not change much as shown in Fig. 9. The increase of the length of the free surface also provides more spaces for adjusting the small-sized products.

Although satisfactory results have been obtained by using isothermal fluid model and viscous material constitutive model, non-isothermal fluid model and viscoelastic material constitutive model are still necessary for the higher precision extrusion, especially for viscoelastic materials with low power law coefficient. As a non-isothermal generalized Newtonian fluid, the apparent viscosity is related to the temperature in addition to the shear rate. The viscosity temperature dependence is characterized by Arrhenius law:

$$
\mathrm{H}(\mathrm{T})=\exp \left[\alpha\left(\frac{1}{T-T_{0}}-\frac{1}{T_{\alpha}-T_{0}}\right)\right]
$$


where $\alpha$ is the ratio of the activation energy $\left(5.37 \times 10^{3} \mathrm{~J}\right)$ and $T_{\alpha}$ is the reference temperature $\left(300^{\circ} \mathrm{C}\right), T_{0}$ is the absolutely zero temperature $\left(-273.15^{\circ} \mathrm{C}\right)$. Inlet temperature of melts is $300^{\circ} \mathrm{C}$ and the mould temperature is $260^{\circ} \mathrm{C}$. Specific Heat Capacity is $1.70 \mathrm{~J} / \mathrm{g}-{ }^{\circ} \mathrm{C}$, Thermal Conductivity is 0.173 $\mathrm{W} / \mathrm{m}-\mathrm{K}$, and coefficient of thermal expansion is $65.0 \mu \mathrm{m} / \mathrm{m}-{ }^{\circ} \mathrm{C}$.

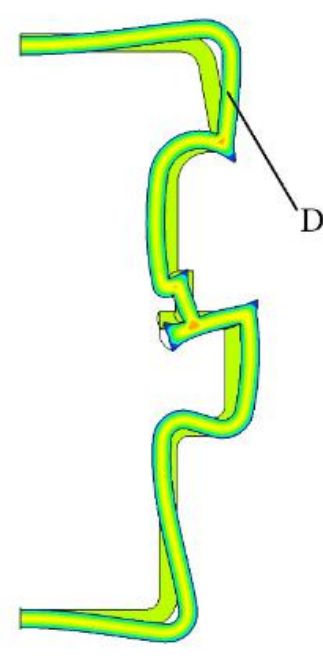

$30 \mathrm{~mm}$

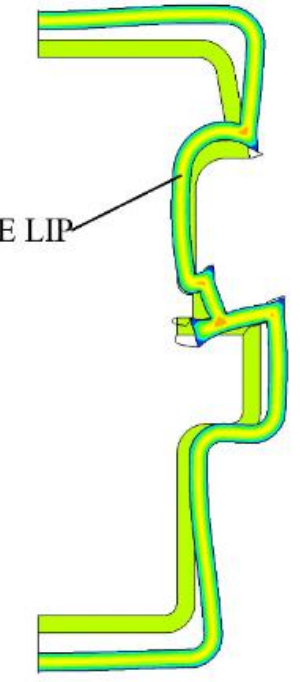

$120 \mathrm{~mm}$

Length of FREE JET

Fig. 9: Die Lip gap Compared (Inlet volumetric flow rate $\mathrm{Q}=1250 \mathrm{~mm}^{3} / \mathrm{s}$ )

The results of a non-isothermal simulation are shown as in Fig. 10. The profile of the die lip obtained by non-isothermal simulation and isothermal simulation are similar. Meanwhile, the highspeed zone is also high temperature zone. The maximum temperature is $270^{\circ} \mathrm{C}$, which is bigger than mould temperature. This means that the choice of mould temperature is reasonable. Through nonisothermal simulation, we can get more accurate analysis results. Therefore, it is necessary to adopt non-isothermal simulation for the die with less space for adjustment.
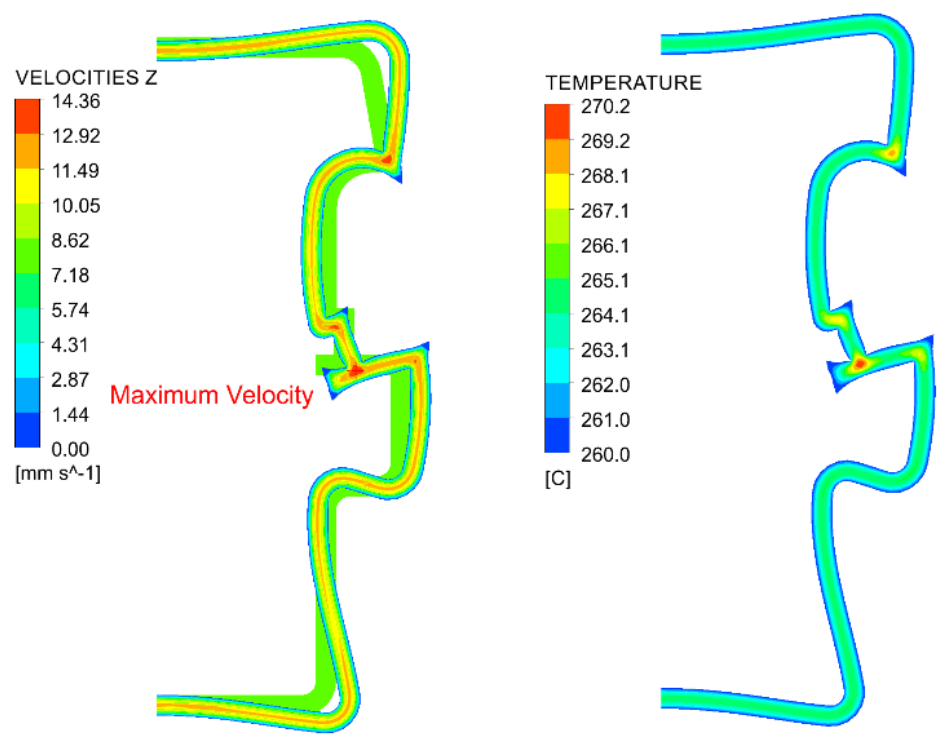

Fig. 10. Velocity and temperature distribution of the enlarged die lip (Non-isothermal). 


\section{Experimental Evaluation}

Extrusion experiment was implemented on the actual extrusion production line of Shanghai Bethlehem Plastic Co. Ltd. For the experimental study, a $\Phi 65 \mathrm{~mm}$ single screw extruder machine (Maker: Jiangsu Faygo Union Machinery Co., Ltd.). The experimental extrusion die shown in Fig. 11(a) was manufactured according to drawing of extrusion die shown in Fig. 11(c), in which the profile of the enlarged die lip gap (shown in Fig. 7) is adopted. The experiment has the process parameters as follows. The Inlet volumetric flow rate is $1250 \mathrm{~mm} / \mathrm{s}$, and the drawing speed is 10 $\mathrm{mm} / \mathrm{s}$. The length of the die 1 to die 4 is $60 \mathrm{~mm}, 25 \mathrm{~mm}, 35 \mathrm{~mm}$, and $25 \mathrm{~mm}$, respectively. Meanwhile, the distance between die lip and calibrator is $30 \mathrm{~mm}$.

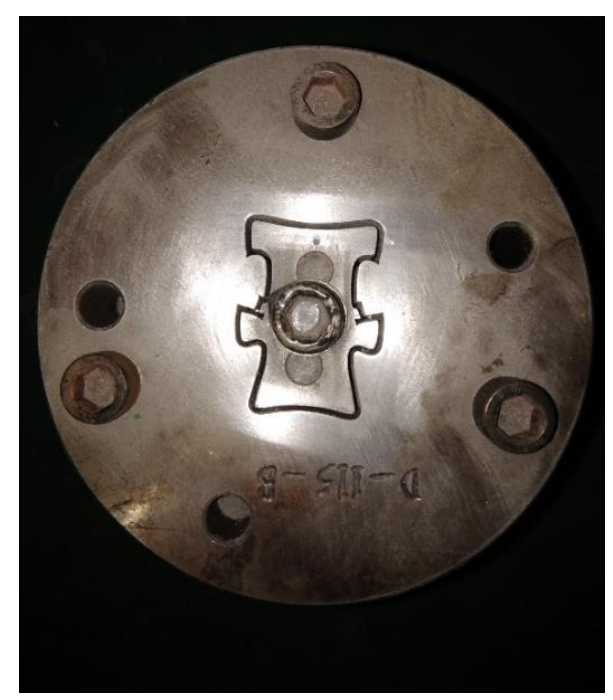

(a)

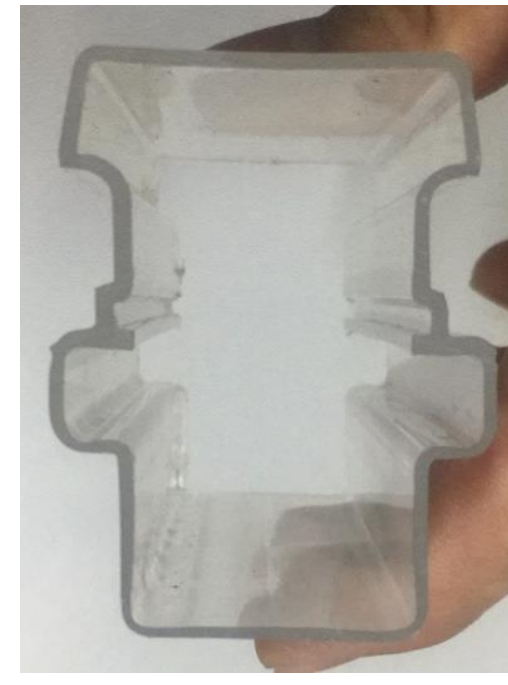

(b)

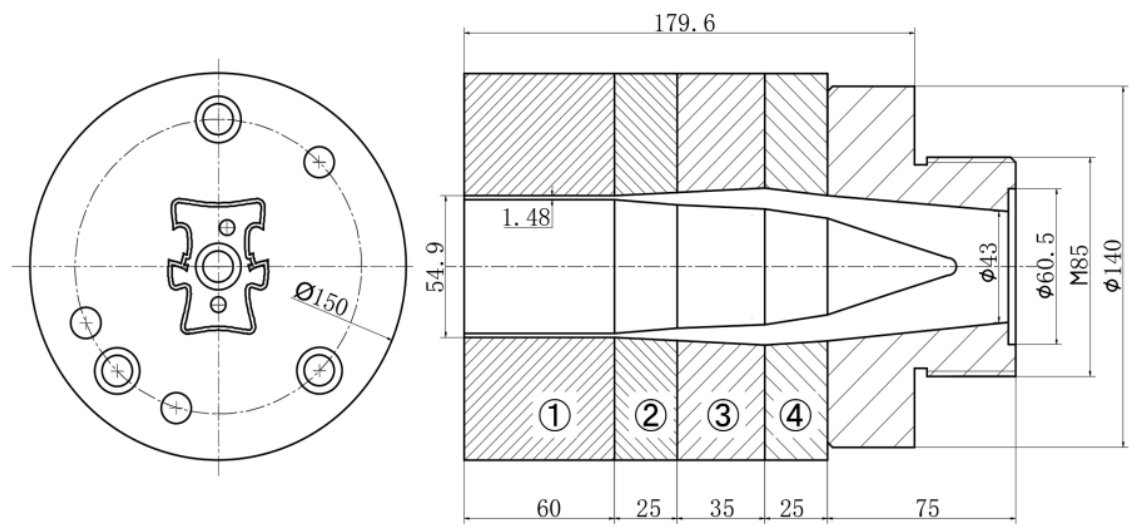

(c)

Fig. 11: Experiment results (a) Experimental Extrusion die; (b) Extrudate; (c) Drawing of extrusion die.

The experimental results show a good product appearance and dimensional accuracy, which is shown in Fig. 11(b). According to the experiment results, the extrusion die designed by the improved inverse method is qualified and cogent for the hollow profile extrusion. Because the overall profile of the extruded part is rectangular, it is similar to the literature [1]. In the case of a square profile, the die exit required to attain a square profile is not square due to the influence of die swell, as illustrated by Professor Kostic [1]. Therefore, the extrudate is regular but the required die shape is irregular. 
Three samples of extruded parts, named A, B and C, were selected for measurement. The crosssectional geometry and tolerance requirements of the product are shown in Fig. 1, and the target values are also listed in Table 2. It can be seen from the table that all dimensions are within the tolerance range, however, some dimensions such as D1 and D2 are close to the lower limit, and D4 is close to the upper limit, but the overall trend of the same dimension is basically the same.

Table 2. Target value and measured value of extruded parts

\begin{tabular}{ccccc}
\hline No. & $\begin{array}{c}\text { Target Value } \\
{[\mathrm{mm}]}\end{array}$ & $\begin{array}{c}\text { Measurement (A) } \\
{[\mathrm{mm}]}\end{array}$ & $\begin{array}{c}\text { Measurement (B) } \\
{[\mathrm{mm}]}\end{array}$ & $\begin{array}{c}\text { Measurement (C) } \\
{[\mathrm{mm}]}\end{array}$ \\
\hline D1 & $35.4 \pm 0.5$ & 34.97 & 34.93 & 34.99 \\
D2 & $37.2 \pm 0.5$ & 36.99 & 36.91 & 36.93 \\
D3 & $24.7 \pm 0.45$ & 24.96 & 24.77 & 24.84 \\
D4 & $49.6 \pm 0.5$ & 49.98 & 49.93 & 50.01 \\
D5 & $26.2 \pm 0.45$ & 26.47 & 26.47 & 26.47 \\
D6 & $25.9 \pm 0.45$ & 25.85 & 26.10 & 25.77 \\
D7 & $1.9+0.4 /-0$ & 1.98 & 2.06 & 2.05 \\
\hline
\end{tabular}

The same three samples of extruded parts, named A, B and C, were used to measure the thickness distribution of the part. The expected thickness of extruded parts is $1.5 \pm 0.2 \mathrm{~mm}$. The positions of all measurement points are shown in Fig 12.

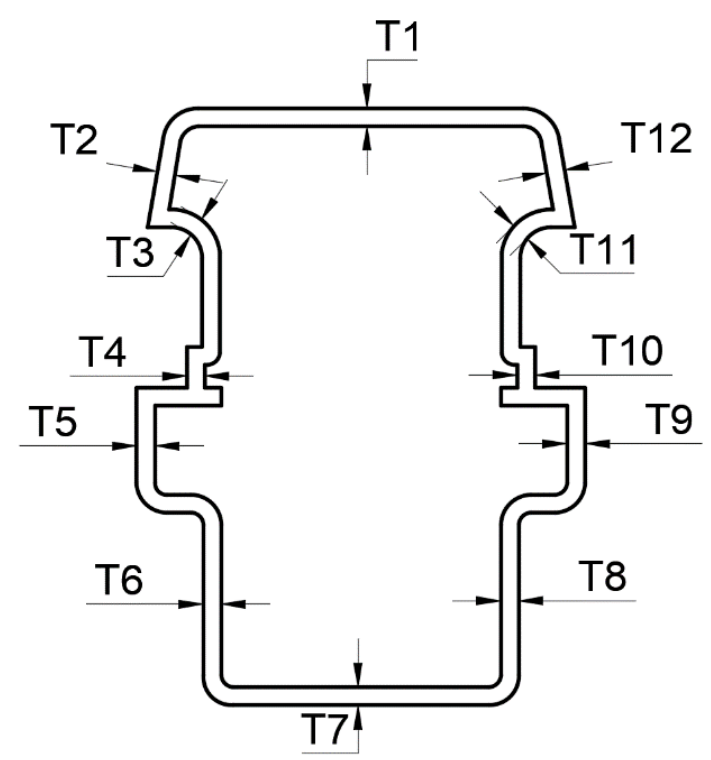

Fig. 12: Twelve Position Points in Cross Section of Extruded Parts

It can be seen from the Table 3 that all dimensions are within the tolerance range, some dimensions such as T5, T6 and T12 are close to the lower limit. The reason for this problem may be that the flow resistance in these areas is large and needs to be improved in the subsequent repair process. 
Table 3. Measured value of twelve position points in cross section of extruded parts

\begin{tabular}{cccc}
\hline No. & $\begin{array}{c}\text { Thickness (A) } \\
{[\mathrm{mm}]}\end{array}$ & $\begin{array}{c}\text { Thickness (B) } \\
{[\mathrm{mm}]}\end{array}$ & $\begin{array}{c}\text { Thickness (C) } \\
{[\mathrm{mm}]}\end{array}$ \\
\hline T1 & 1.40 & 1.40 & 1.31 \\
T2 & 1.48 & 1.48 & 1.50 \\
T3 & 1.48 & 1.49 & 1.34 \\
T4 & 1.51 & 1.59 & 1.54 \\
T5 & 1.35 & 1.40 & 1.36 \\
T6 & 1.35 & 1.39 & 1.35 \\
T7 & 1.50 & 1.41 & 1.47 \\
T8 & 1.47 & 1.38 & 1.38 \\
T9 & 1.47 & 1.43 & 1.40 \\
T10 & 1.59 & 1.66 & 1.65 \\
T11 & 1.55 & 1.45 & 1.48 \\
T12 & 1.32 & 1.31 & 1.35 \\
\hline
\end{tabular}

\section{Conclusions}

An improved inverse design method with CFD simulation shows advantages for thin-wall hollow profile extrusion die design. With complexity cross-section of a profile, the design can compensate the extrusion deformation and thickness change to get the right dimension of the product more effectively. It can be concluded:

i. Simulation results show that the inlet flow rate and length of free jet should be appropriately chosen, which leads to proper thickness and geometry profile enlargement of the die lip gap.

ii. By using design criteria of the inverse design method of extrusion die, the optimal solution of the extrusion die design can be found.

Compared to the flow balance method used widely at present, the inverse design method does not need sectional areas divided and the complicated optimization procedure. As a direct result, the computational efficiency can be significantly improved. However, for the thin wall extrudate with significantly different thickness sections, the inverse design method needs to improve its efficiency. The best choice is to achieve flow balance firstly by using optimization design methods, and then employ the improved inverse design method to obtain the final design of extrusion die. This will improve the design accuracy and minimise the manufacture risks, which has been proved by this study.

\section{Acknowledgment}

This work is supported by Six Talent Peaks Project in Jiangsu Province (Grant No. RJFW-051) and National Natural Science Foundation of China (Grant No. 51605414).

\section{References}

[1] Kostic, M. M., \& Reifschneider, L. G. (2006). Design of extrusion dies. Encyclopedia of chemical processing, 10, 633-649. 
[2] Rauwendaal, C. (2014). Polymer extrusion. Carl Hanser Verlag GmbH Co KG.

[3] Carneiro, O. (Ed.). (2012). Design of extrusion forming tools. Smithers Rapra.

[4] Cho, J. R., \& Choi, J. H. (2016). Numerical investigation of weather strip extrusion forming process by thermal flow analysis. The International Journal of Advanced Manufacturing Technology, 87(9-12), 2841-2851.

[5] Fragassa, C., \& Ippoliti, M. (2016). Technology assessment of tire mould cleaning systems and quality finishing. International Journal for Quality Research, 10(3), 523-546.

[6] Mu, Y., Hang, L., Chen, A., Zhao, G., \& Xu, D. (2017). Influence of die geometric structure on flow balance in complex hollow plastic profile extrusion. The International Journal of Advanced Manufacturing Technology, 91(1-4), 1275-1287.

[7] Tanner RI (1970) A theory of die-swell. J Polym Sci Part A 8:2067-2078

[8] Carneiro, O. S., \& Nobrega, J. M. (2004). Recent developments in automatic die design for profile extrusion. Plastics, Rubber and Composites, 33(9-10), 400-408.

[9] Pittman, J. F. T. (2011). Computer-aided design and optimization of profile extrusion dies for thermoplastics and rubber: a review. Proceedings of the Institution of Mechanical Engineers, Part E: Journal of Process Mechanical Engineering, 225(4), 280-321.

[10] Gonçalves, N. D., Carneiro, O. S., \& Nóbrega, J. M. (2013). Design of complex profile extrusion dies through numerical modeling. Journal of Non-Newtonian Fluid Mechanics, 200, 103-110.

[11] Gonçalves, N. D., Teixeira, P., Ferrás, L. L., Afonso, A. M., Nóbrega, J. M., \& Carneiro, O. S. (2015). Design and optimization of an extrusion die for the production of wood-plastic composite profiles. Polymer Engineering \& Science, 55(8), 1849-1855.

[12] Gonçalves, N. D., Pereira, S. P., Ferrás, L. L., Nóbrega, J. M., \& Carneiro, O. S. (2015). Using the GPU to Design Complex Profile Extrusion Dies. International Polymer Processing, 30(4), $442-450$.

[13] Szarvasy, I., Sienz, J., Pittman, J. F. T., \& Hinton, E. (2000). Computer aided optimisation of profile extrusion dies: definition and assessment of the objective function. International Polymer Processing, 15(1), 28-39.

[14] Carneiro, O. S., Nóbrega, J. M., Pinho, F. T., \& Oliveira, P. J. (2001). Computer aided rheological design of extrusion dies for profiles. Journal of materials processing technology, 114(1), 75-86.

[15] Pauli, L., Behr, M., \& Elgeti, S. (2013). Towards shape optimization of profile extrusion dies with respect to homogeneous die swell. Journal of Non-Newtonian Fluid Mechanics, 200, 79-87.

[16] Siegbert, R., Behr, M., \& Elgeti, S. (2016). Die swell as an objective in the design of polymer extrusion dies. In AIP Conference Proceedings (Vol. 1769, No. 1, p. 140003). AIP Publishing.

[17] Yilmaz, O., Gunes, H., \& Kirkkopru, K. (2014). Optimization of a profile extrusion die for flow balance. Fibers and Polymers, 15(4), 753-761.

[18] Carneiro, O. S., Rajkumar, A., Ferrás, L. L., Fernandes, C., Sacramento, A., \& Nóbrega, J. M. (2017). Computer aided die design: A new open-source methodology. In AIP Conference Proceedings (Vol. 1843, No. 1, p. 030008). AIP Publishing.

[19] Rajkumar, A., Ferrás, L. L., Fernandes, C., Carneiro, O. S., Becker, M., \& Nóbrega, J. M. (2017). 
Design Guidelines to Balance the Flow Distribution in Complex Profile Extrusion Dies. International Polymer Processing, 32(1), 58-71.

[20] Covas, J. A., Carneiro, O. S., \& Brito, A. M. (1991). Designing extrusion dies for thermoplastics. Journal of Elastomers \& Plastics, 23(3), 218-238.

[21] Legat, V., \& Marchal, J. M. (1993). Die design: an implicit formulation for the inverse problem. International journal for numerical methods in fluids, 16(1), 29-42.

[22] Gifford, W. A. (2003). Compensating for die swell in the design of profile dies. Polymer Engineering \& Science, 43(10), 1657-1665.

[23] Ordieres, J., López, L. M., Bello, A., \& Garcia, A. (2003). Intelligent methods helping the design of a manufacturing system for die extrusion rubbers. International Journal of Computer Integrated Manufacturing, 16(3), 173-180.

[24] Vaddiraju, S. R., Kostic, M., Rykalin, V., Reifschneider, L. G., Pla-Dalmau, A., \& Bross, A. (2004). Extrusion simulation and experimental validation to optimize precision die design. In ANTEC-CONFERENCE PROCEEDINGS-. (Vol. 1, pp. 76-80).

[25] Debbaut, B., \& Marchal, T. (2008). Numerical simulation of extrusion process and die design for industrial profile, using multimode pom-pom model. Plastics, rubber and composites, 37(24), 142-150.

[26] Yanke, J., Fezi, K., Trice, R. W., \& Krane, M. J. M. (2015). Simulation of slag-skin formation in electroslag remelting using a volume-of-fluid method. Numerical Heat Transfer, Part A: Applications, 67(3), 268-292.

[27] CAMPUS 5.2, http://www.campusplastics.com, Computer aided material preselection by uniform standards, accessed 26 June 2018.

[28] Nóbrega, J. M., Carneiro, O. S., Oliveira, P. J., and Pinho, F. T. (2003), Flow balancing in extrusion dies for thermoplastic profiles: part I: Automatic Design, International Polymer Processing, 18(3), 298-306

[29] Dai Y K, Zhou C X, Yu W., Inverse designing simulation of extrusion die of auto rubber seal and verifications, Plastics, rubber and composites, 2007, 36(4): 141-148.

[30] Legat, V., \& Marchal, J. M. (1992). Prediction of three-dimensional general shape extrudates by an implicit iterative scheme. International journal for numerical methods in fluids, 14(5), 609625.

[31] Goublomme, A., Draily, B., \& Crochet, M. J. (1992). Numerical prediction of extrudate swell of a high-density polyethylene. Journal of non-Newtonian fluid mechanics, 44, 171-195.

[32] Ajiboye, J. S., \& Adeyemi, M. B. (2007). Upper bound analysis for extrusion at various die land lengths and shaped profiles. International journal of mechanical sciences, 49(3), 335-351. 